\title{
Efforts to Promote Global Education in Japan: The Case of Tottori University and Overseas Practical Education Programs
}

\author{
Roxana Y. Parada ${ }^{1 *}$, Reiko Ikeda ${ }^{1 *}$, Takayuki Ando ${ }^{1}$, Masako Hishida ${ }^{1}$, Hiroshi Takeda ${ }^{1}$, Dagnachew Aklog ${ }^{1}$, \\ Kurie Otachi ${ }^{1}$ \& Kumi Yasunobu ${ }^{1}$ \\ ${ }^{1}$ Center for International Affairs, Tottori University, 4-101 Koyama-Minami, Tottori 680-8550, Japan \\ *These authors contributed equally to this work. \\ Correspondence: Roxana Y. Parada, Center for International Affairs, Tottori University, Japan. Tel: \\ 81-857-31-5659.
}

Received: May 9, 2018

doi:10.5539/jel.v7n5p62
Accepted: June 8, 2018 Online Published: June 18, 2018

URL: https://doi.org/10.5539/jel.v7n5p62

\begin{abstract}
Participation in overseas programs has recently increased as an international strategy worldwide. However, Japan has been the exception, because the number of Japanese students studying abroad has decreased over the last decade. The Japanese government and universities began efforts to motivate Japanese students to gain international experience. However, efforts to measure the impact of overseas programs other than in English proficiency have been limited. This paper reports the benefits of three types of overseas short-term programs offered by Tottori University (TU) to support Japanese students in studying abroad through the Global Getaway Program (GGP), emphasizing practical training in developing countries. Data for this study were collected from students from 2006 to 2011 before the GGP and 2012 to 2016 after its implementation. Students were tested before and after participating in overseas short-term programs, and results were compared with those who did not participate. The questionnaire survey carried out revealed significant differences in all global competences skills between students who attended overseas programs and those that did not. In addition, after participating in the overseas program, students understood i, why English as a tool for communication will help them grow as internationally minded future leaders, ii, how foreign languages can lead to overseas practical skills, and iii, the importance of field practice as opposed to knowledge only acquired in the classroom. The achievement of this study increases the value of overseas training for the younger Japanese generation and their perception of developing advanced thinking abilities through practical education in developing countries.
\end{abstract}

Keywords: developing country, global human resources, higher education, overseas short-term programs, practical education, Tottori University, Japan

\section{Introduction}

Demographics, economic pressure, and globalization in higher education are the main reasons for students' mobility worldwide. According to The United Nations Educational, Scientific and Cultural Organization ([UNESCO], 2013) the number of outbound students has increased from 1.3 million in 1990 to 4.3 million in 2011. In the past, students' mobility focused on English-speaking countries. However, in recent years, the number of students from Asia and the Pacific region has also increased, and 53\% of all students enrolled in higher education in 2011 were from China, India, and Korea (Organization for Economic Cooperation and Development [OECD], 2012; Nam, 2018).

The speed of population decline and aging in developed and developing countries is another relevant issue affecting higher education worldwide. Japan has a rapidly aging population and low birth rate, resulting in a decrease of the youth and working age populations. The decreasing number of young people and the emergence of new universities has led to an over-supply of universities in Japan. Therefore, Japan is moving towards enhancing or cultivating the capabilities of the younger generation through the internationalization of its universities (Kuwamura, 2009; Shimomura, 2013).

The Ministry of Justice Immigration Bureau and Ministry of Education, Culture, Sports, Science and Technology (MEXT) have implemented changes in the education-oriented immigration policy and internationalization of higher education in Japan. Notably, the number of international students increased from 10,428 in 1983 to 
141,747 in 2010 (Japanese Students Services Organization [JASSO], 2010), and the number of Japanese students abroad has gradually increased from 18,066 in 1983 to 82,945 in 2004 (JASSO, 2015). Nevertheless, by 2010 the number of Japanese students decreased to 58,060 (JASSO, 2015), because the English programs offered at selected universities were mainly used to attract international students, not necessarily Japanese students, among other factors (Yonezawa, 2014; Bradford, 2015). Therefore, in 2011, the Japanese government initiated new growth strategy measures to increase inbound and outbound student mobility as well as the "Global Human Resources Development" strategy (Yonezawa, 2014). In total, 37 universities were selected to participate in the "Top Global University Project". In addition, three other projects were launched to support the internationalization of Japanese universities and Japanese students to study abroad, namely the "Global 30 Project," the "Go Global Japan Project," and the "Re-Inventing Japan Project" (MEXT, 2014; Rose \& McKinley, 2018).

In higher education, MEXT stated that the acquisition of knowledge and skills (theory) is as important as the ability to practice and apply the knowledge and skills learned (practice) and the development of global skills to tackle and solve arising problems. Therefore, MEXT highlights the necessity of developing global human resources with independent and autonomous thinking abilities, and the capacity to create new products and services and work with others for a new and more prosperous society (htttp://www.mext.go.jp/b_menu/shingi/chukyo0/toushin).

Analyzing higher education in Japan, various initiatives have been implemented to nurture global human resources by exploiting the characteristics of each university (Lawson, 2012; N. Okada \& A. Okada, 2013). However, efforts in global education in many universities have been equated to English education (Seargeant, 2011; Hashimoto, 2013; Phan, 2013; Rose \& McKinley, 2018).

Certainly, the focus on English education is one characteristic of educational reform in Japan and other Asian countries (Kirkpatrick, 2011). Japan has established English as a subject in elementary school and promotes the recruitment of foreign teachers to handle it (Butler, 2007). Indeed, educators must ensure that young people acquire English language skills, as it is the most spoken language worldwide, to develop a future global society. However, we need to understand why it is necessary to prioritize nurturing English comprehension skills as part of communication skills. The reason is that in a global society, we need to share and coexist with people with different cultures or values; therefore, the receiving party of education must understand that improving communication skills including English language skills will help them become globalized human resources (Ike, 1995; Nakamura, 2002; Horiguchi et al., 2015).

In 2012, Tottori University (hereinafter referred to as TU) started the Global Gateway Program (GGP) for the "Promotion of Global Human Resources Development" under the "Go Global Japan Project" (GGJ) from 2012, which was completed in 2016 (Hishida, 2015). Most of the Japanese universities belonging to the GGJ offer overseas programs to foster English communication skills as the main subject (https://www.anesta.co.jp/user/cn10/pg202.html). Conversely, since $2006 \mathrm{TU}$ has promoted its unique overseas practical education training program "Towards a Framework of Sustainable Society in Harmony with Nature" in developing countries as an international strategy to foster students with advanced thinking abilities and communication skills, including English. From 2011 to 2016, before and through the implementation of the GGP, TU developed three types of short-term programs, i, Language training programs offered by sister universities in Canada, the United States and Australia. Students who attend these programs are mainly interested to develop their practical English skills, ii, Language training and cross-cultural programs offered in Malaysia and Taiwan. Students who attend these programs, in addition to language skills development, can improve their understanding of culture, tradition and history, and iii, a new overseas practical education program in Uganda was also launched (Table 1).

The overseas practical education programs in Mexico and Uganda, unlike language programs and language/cross-cultural programs, students who attend these programs enhance their understanding of global issues such as desertification, food shortage, wildlife conservation, and a wide range of other topics covering the socio-economic, cultural and historical aspects of each country. All lectures, field research, and other activities are conducted in English and students can develop their basic ability to identify problems and create new ideas to solve them. At TU, the three types of programs enable Japanese students to acquire global strength, empower execution based on autonomy and collaboration in a diverse environment, and encourage global citizens with high ethical and social standards, including communication skills in English.

This paper focuses on the results of our three types of overseas short-term programs (from one to three months) from 2006 to 2016 at TU before and after the implementation of the GGP. The study also stresses the positive 
impact of overseas short-term programs on Japanese students in developing the global management skills required for a future global society. In addition, how TU is working towards its international strategy through overseas practical education is discussed.

Table 1. Short-term programs offered by Tottori University before $(*)$ and after (**) GGP implementation (FY2006-2016)

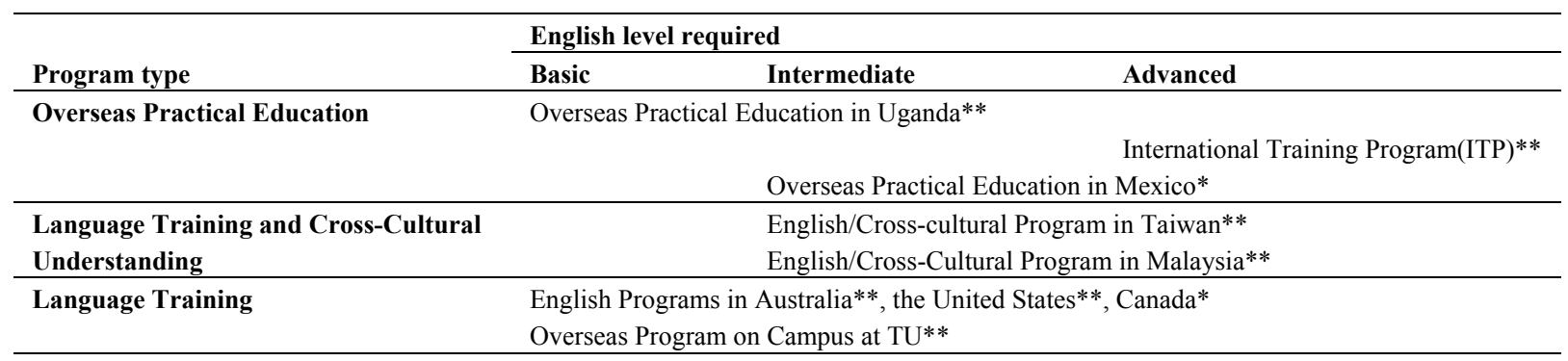

\section{Methodology, Participants, Data Collection and Analysis}

The primary data for this study were collected from 2006 to 2016 from students who participated in the overseas short-term programs from 2006 to 2011 before the GGP, and from 2012 to 2016 after its implementation. Quantitative data from two surveys, the Global Human Power Indicator survey (Global Competence Assessment Method) developed in this study according to the Council of Europe (CEFR, 2011) as well as the International Communication Skills survey were employed to evaluate the effect of the overseas and domestic short-term programs on Japanese undergraduate students. In the Global Competence Assessment questionnaire, global management skills are delineated into 11 levels, and the global literacy and global communication skills into 6 levels. The Global Human Power Indicator survey was distributed via the university homepage, and 257 (GGP participants and others who participated in overseas programs) undergraduate students who participated in overseas short-term programs in 2014 and another one in 2015 were asked to complete the questionnaire. The survey for International Communication Skills was distributed to 579 (GGP and others who participated in overseas programs) undergraduate students at the time of their graduation in 2016 at the Faculties of Agriculture, Engineering and Regional Sciences. Of these, 142 students participated in overseas short-term programs and 437 did not. A significant difference between the means was determined using the Student's t-test and Mann-Whitney U-test.

\section{Findings}

\subsection{Programs and Japanese Students' Mobility Before and After the GGP}

To promote international training among Japanese students, TU launched two overseas programs. The Overseas Practical Education Program started in 2006 in Mexico, and The English Language Program in Canada in 2011. After the implementation of the GGP, English Language Program in the United States and Australia, as well as the new English Language with Cross-Cultural Understanding programs were launched in 2012 in Malaysia and Taiwan. The most recent program started in 2015, namely the Overseas Practical Education Program in Uganda. TU currently offers eight short-term overseas programs to Japanese students (Figure 1a). As a result, the number of Japanese students interested in studying abroad has increased significantly over the last six years (Figure 1b). Statistical analysis showed the p-value of 0.003 was less than alpha level of 0.01 . Therefore, there was a significant difference before and after the implementation of the GGP (Figure 1c), indicating that the implementation of the GGP made it easier for students to participate in study abroad programs and, by preparing more options to study abroad, the GGP had an important role in providing support for students to undertaking overseas short-term programs. It is worth mentioning that the approach to safety management for students in travelling to developing countries from TU, differs to the activities/policies of other universities in Japan which offer one-hour long safety seminars provided by a security companies, at TU those who attend overseas programs are required to take a class called "Overseas Safety Management" as a cumpulsory subject. This class is given by professors of TU and specialists from security companies. This consists of Safety Information, International Law, Traffic Rules, Health including Mental Health, Money (robbery, theft, credit card, etc.), Emergencies, Evacuations, and Crisis Communication. Since the GGP started, the number of students who took this class has reached 1,130 in total. 


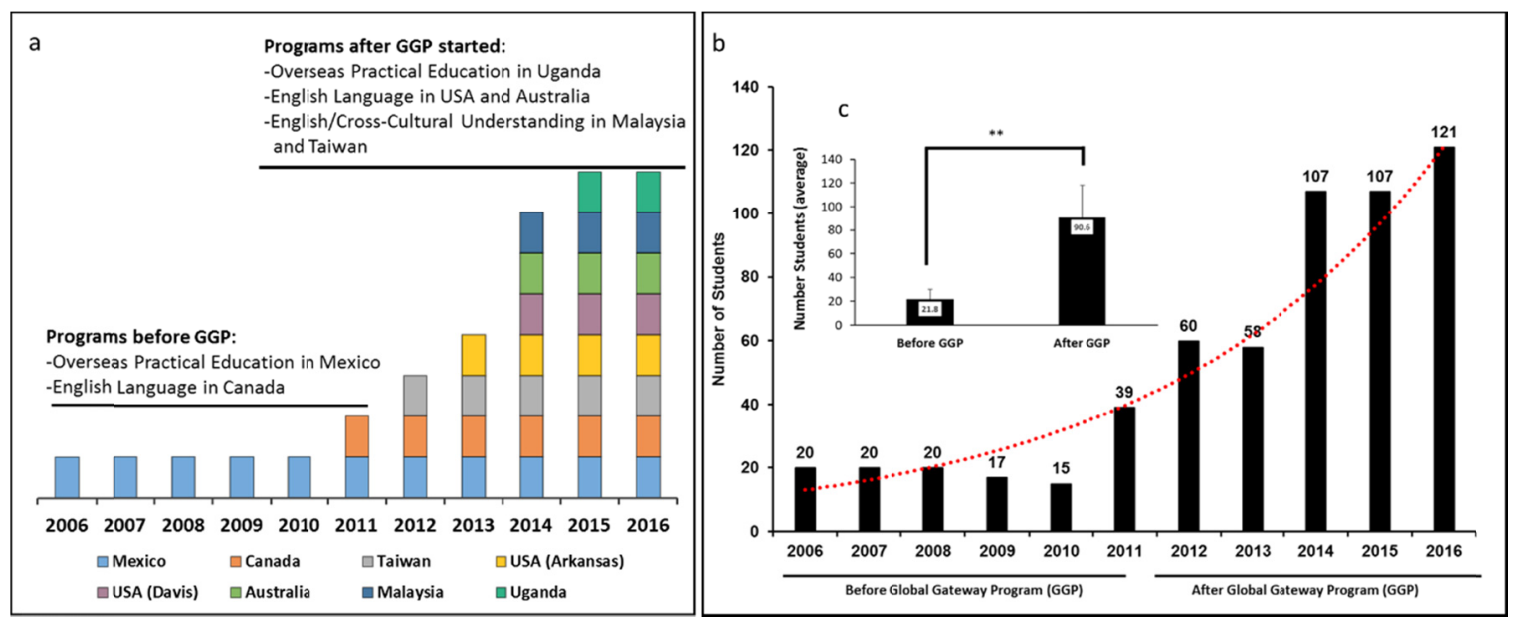

Figure 1. Trend of programs and outbound students' mobility at TU from 2006 to 2016. (a) Short-term overseas programs at TU before and after implementation of the GGP. (b, c) Trend of Japanese students studying abroad before and after GGP implementation.

Note. The values represent the average and standard deviation. The asterisk indicates significant differences before and after the implement of the GGP (**t-test, $\mathrm{p}<0.01$ : Before GGP implementation $\mathrm{X}=21.8, \mathrm{SD}=8.2$; After GGP implementation $\mathrm{X}=90.6, \mathrm{SD}=27.7$, t-value -5.048 , p-value 0.003).

\subsection{Gender, Faculties and Grades of Japanese Students Participating in Short-Term Overseas Programs}

In terms of gender, during the period 2006-2011 before GGP implementation, there was no significant difference in the number of females and males enrolled in overseas programs (Figure 2a). However, the number of females increased significantly after the GGP was implemented $(55.5 \%)$ compared to males (44.5\%). The p value of 0.048 was less than the alpha level of 0.05 , therefore, there was a significant difference between males and females before GGP and after its implementation (Figure $2 b$ ).

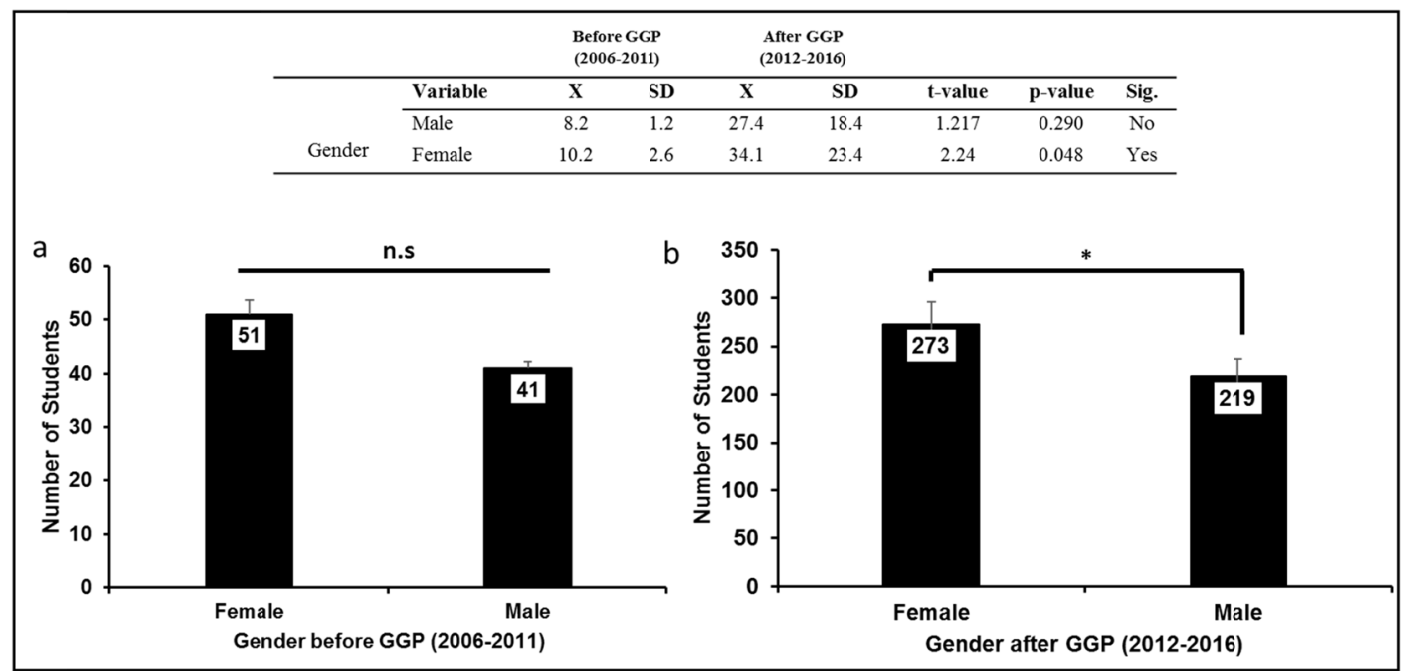

Figure 2. Gender of short-term overseas participants from TU (a) before GGP and (b) after GGP implementation

Note. The values represent the average and standard deviation. The asterisk indicates significant differences between the number of females and males before and after GGP implementation $(* t-t e s t, p<0.05, \mathrm{n} . \mathrm{s}=$ no significant).

We then analyzed the faculties and academic grades of participating students over the last ten years according to the program type and independent of the implementation of the GGP. The Overseas Practical Education Program in Mexico originally focused on the agriculture field and those in the third grade were the target students. As shown in figure 3a, most students who participated in this program were from the Faculty of Agriculture (79.5\%) and some from the Faculties of Regional Sciences (12.5\%), Medicine (4.5\%), or Engineering (3.5\%). 
Furthermore, most participants were third grade students (78.5\%) (Figure 3b). With the new English language programs created by the GGP in Canada, the United States, and Australia, the number of students from the Faculties of Engineering (39.7\%), Medicine and Regional Sciences (18\%) increased compared to that from Agriculture (24.3\%). The number of first $(40 \%)$ and second grade students $(37 \%)$ also increased compared to third grade students (15.3\%) (Figure 3b, 3e). The same tendencies in the first (43.6\%) and second grades (32.3\%) were found for the English language with cross-cultural understanding programs in Malaysia and Taiwan, wherein most participants were from the Faculties of Agriculture (39\%) and Engineering (32.3\%) (Figure 3c, f). By creating three types of overseas programs with different English levels as a requirement of the application, the number of first and second grade students from the Faculties of Engineering and Regional Sciences increased. Noteworthy is that the small number of participants from the Faculty of Medicine is because their curriculum differs from the other faculties and students do not have enough holidays in the spring or summer to participate in overseas programs.

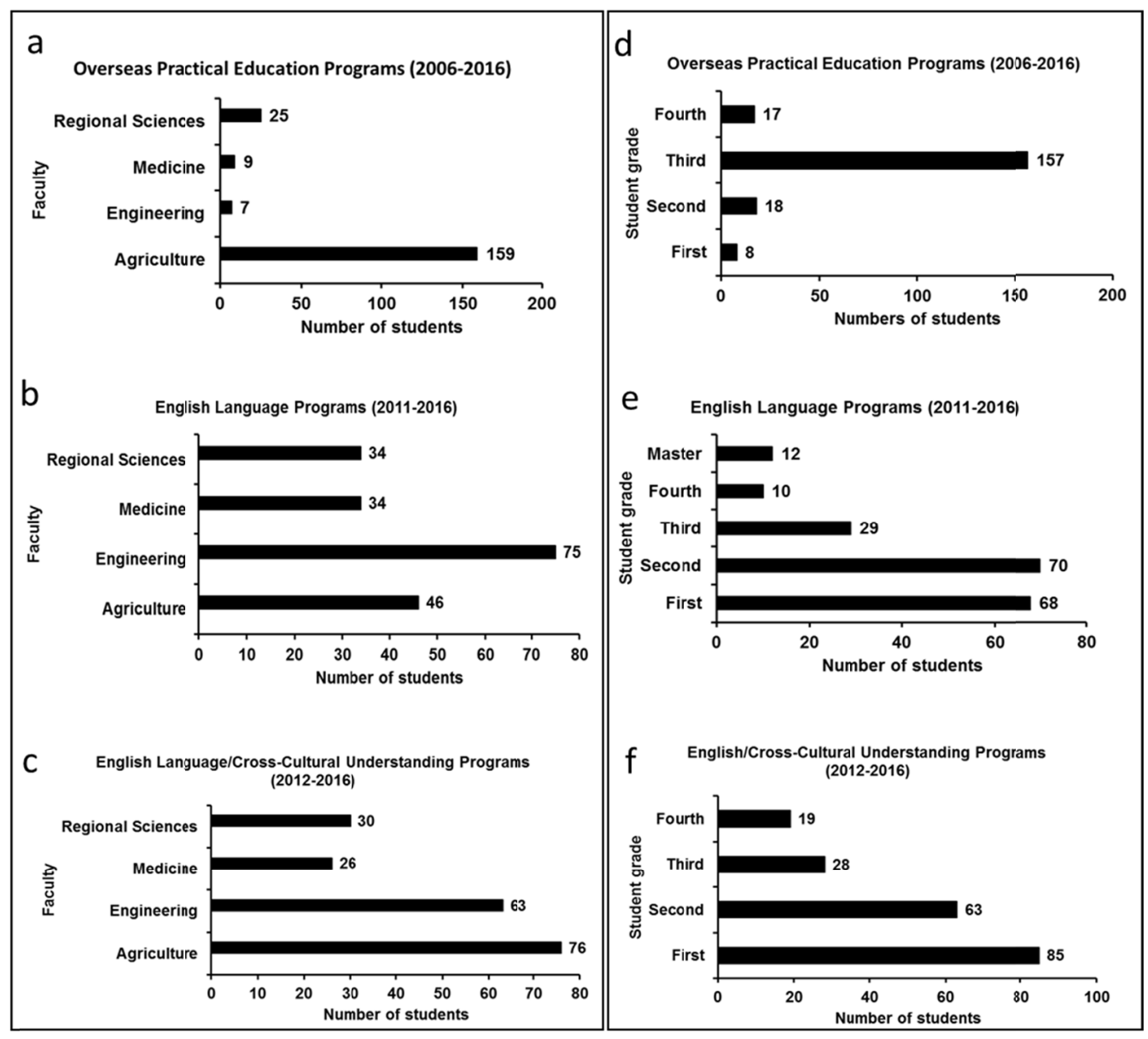

Figure 3. Faculties and academic grades of students who participated in short-term overseas programs at TU

The total student population at TU before and after the implementation of the GGP showed that there is no significant difference between the number of students and their academic grades before GGP and after its implementation (Figure 4a, 4b, Table 2). This result suggests that the participation of first and second grade students increased due to the implementation of the GGP and not due to demographic differences. Nevertheless, there was a statistically significant difference between the number of male and female students before and after the implementation of the GGP (Figure 4a, Table 2), suggesting that female participation may have increased due to i, countries where the new programs were launched are close to Japan, ii, female students are more interested in learning English and experiencing different cultures than male students or iii, the demographic differences before and after the implementation of GGP. Further research is needed to clarify the reasons for the increase of female students in the overseas programs. On the other hand, the number of students from the Faculties of Regional Sciences, Agriculture and Engineering was not significant or significantly reduced, 
respectively (Figure 4c, Table 2), indicating that the demographic differences are not the reason for the increase of students who participated in overseas programs of these faculties.

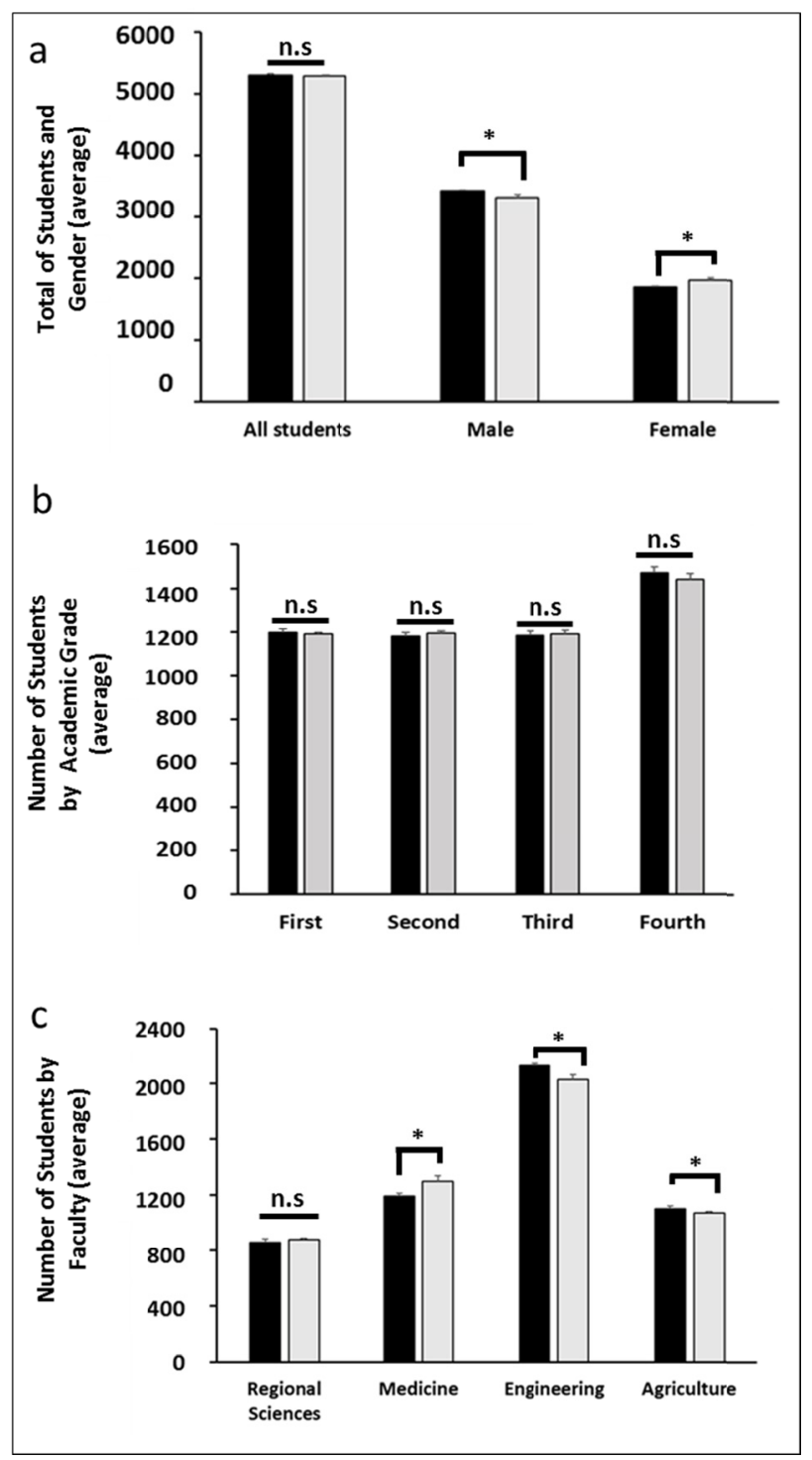

Figure 4. Average of total student population at TU before GGP (2006-2011) and after its implementation (2012-2016). (a) Average number of total student and gender, (b) Average number of students in each faculty (c) Average number of students by academic grades $\left({ }^{*}\right.$ t-test, $p<0.05$, n.s $=$ no significant $)$

Table 2. T-test analysis of total student population at TU before GGP and after its implementation

\begin{tabular}{|c|c|c|c|c|c|c|c|c|}
\hline & \multirow[b]{2}{*}{ Variable } & \multicolumn{2}{|c|}{ Before GGP (2006-2011) } & \multicolumn{2}{|c|}{ After GGP (2012-2016) } & \multirow[b]{2}{*}{ t-value } & \multirow[b]{2}{*}{ p-value } & \multirow[b]{2}{*}{ Sig. } \\
\hline & & $\mathbf{X}$ & SD & $\mathbf{X}$ & SD & & & \\
\hline Population & All students & 5292.0 & 29.9 & 5286.2 & 5.8 & 0.442 & 0.676 & No \\
\hline \multirow{2}{*}{ Gender } & Male & 3433.5 & 12.8 & 3320.0 & 49.8 & 4.679 & 0.009 & Yes \\
\hline & Female & 1858.5 & 17.9 & 1966.2 & 48.9 & 4.400 & 0.007 & Yes \\
\hline \multirow{4}{*}{ Faculty } & Reg. Sci. & 860.8 & 20.6 & 879.0 & 8.2 & -1.878 & 0.102 & No \\
\hline & Medicine & 1213.0 & 12.9 & 1300.6 & 37.0 & -5.505 & 0.002 & Yes \\
\hline & Engineering & 2132.0 & 17.7 & 2028.6 & 34.6 & 5.963 & 0.001 & Yes \\
\hline & Agriculture & 1103.8 & 17.6 & 1072.0 & 9.4 & 3.608 & 0.006 & Yes \\
\hline \multirow{4}{*}{$\begin{array}{l}\text { Academic } \\
\text { Grade }\end{array}$} & First & 1197.0 & 16.1 & 1189.2 & 7.6 & 0.999 & 0.350 & No \\
\hline & Second & 1180.3 & 17.9 & 1192.0 & 12.2 & -1.21 & 0.255 & No \\
\hline & Third & 1184.7 & 18.9 & 1191.4 & 16.9 & -0.584 & 0.573 & No \\
\hline & Fourth & 1471.5 & 26.8 & 1441.4 & 27.9 & 1.725 & 0.118 & No \\
\hline
\end{tabular}

Note. $\mathrm{p}<0.05$ 


\subsection{Positive Effect of Short-Term Programs on Japanese Students}

To investigate if students acquired the global education skills proposed by our university as part of the Global Human Resource Development program in 2012 (http://www.jsps.go.jp/j-gjinzai/data/shinsa/h24), we developed a global competence assessment method according to the Council of Europe (CEFR, 2011). The results from 257 undergraduate students who participated in overseas short-term programs during 2014 and 2015 revealed an increase in self-perceived abilities (Table 3). In addition, a significant difference in all global abilities was observed in the students before and after participating in the overseas programs, indicating the positive impact of short-term overseas programs on Japanese students.

Furthermore, at the time of graduation in 2016, we assessed the growth of global communication skills through a survey of 579 undergraduate students from the Faculties of Agriculture, Engineering and Regional Sciences, of which 142 participated in the overseas and 437 did not. The items measured in survey were progress in a foreign language (Figure 5a), confidence to make friends with foreign people (Figure 5b), understanding of different cultures (Figure 5c), understanding of global issues (Fig. 5d), and confidence to challenge the globalized society (Figure 5e). Significant differences were observed between students who participated in one or more overseas programs and those who did not, indicating that short-term overseas programs positively affect on Japanese students. In addition, they gained experience in international travel, personal confidence, and the ability to communicate in a different language.

Table 3. Comparison of global competences abilities before and after students' participation in short-term overseas programs

\begin{tabular}{lll}
\hline & \multicolumn{2}{c}{ Overseas study } \\
\cline { 2 - 3 } & Before & After \\
\hline Global competences abilities & $* \mathbf{5 . 3}$ & $\mathbf{6 . 6}$ \\
\hline Global human potential & $\mathbf{4 . 5}$ & $\mathbf{5 . 8}$ \\
-Self development capacity & 5.3 & 6.3 \\
-Self management ability & 4.9 & 6.2 \\
-Solving problem & 4.6 & 5.6 \\
\hline Global literacy & $\mathbf{5 . 2}$ & $\mathbf{6 . 5}$ \\
-Culture and social dissemination ability & 4.5 & 5.8 \\
-Global issues understanding & 5.7 & 6.3 \\
-Intercultural understanding & 6.4 & 7.6 \\
-Intercultural empathy & 5.2 & 6.4 \\
\hline Global communication & $\mathbf{4 . 3}$ & $\mathbf{5 . 9}$ \\
-English skills & 3.7 & 5.2 \\
-Multilanguage awareness & 2.0 & 3.1 \\
-Presentation skills & 5.5 & 6.0 \\
-Debate ability & 5.2 & 5.8 \\
-Teamwork and teambuilding skills & 5.1 & 6.3 \\
\hline
\end{tabular}

Note. *Global Capability Assessment Method based on the Common European Framework of Reference Languages (CEFR) (Ando, 2017) $(\mathrm{p}<0.01)(\mathrm{n}=257)$. 


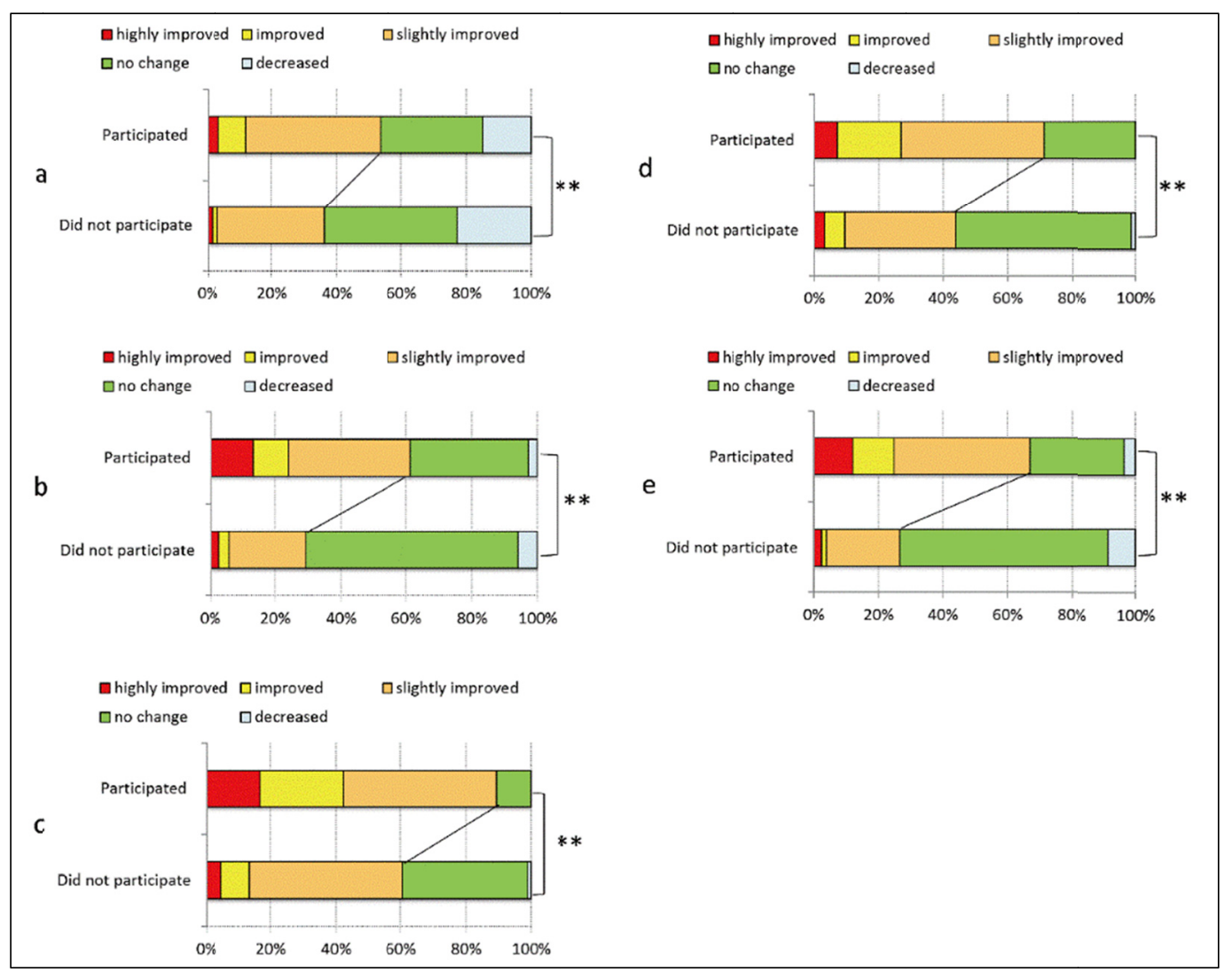

Figure 5. Growth of global competence at the time of graduation in 2016 of TU students. (a) Progress in foreign language ability, (b) Confidence to make friends with foreign people, (c) Understanding of different cultures, (d) Understanding of global issues, and (e) Confidence to challenge the globalized society

Note. Data were analyzed using the Mann Whitney $U$-test $\mathrm{p}<0.01(\mathrm{n}=579)$.

\subsection{Positive Effects of Short-Term Overseas Practical Education Programs on Language Skills}

The overseas practical education programs in Mexico and Uganda are branded under the slogan: "Fusion of Knowledge and Practice." Students participating in these programs are trained to integrate the theoretical knowledge obtained in lecture rooms with practice in the field. The programs are offered in collaboration with other international institutions worldwide. For both countries, students are selected according to their TOEIC (Test of English for International Communication) and grade point average (GPA) scores. For the program in Mexico, selected students spend three months in La Paz Baja California Sur under the supervision of instructors from the Autonomous University of Baja California Sur, Mexico (UABCS); Center for Biological Research of Northwest Mexico, S.C. (CIBNOR); and the University of California, Davis (USA). Lectures are related to various fields in English; however, Spanish and English classes are also offered by professors of the UABCS. Following this, students complete a one-month immersion/homestay with a Mexican host family to practice their Spanish and learn about Mexican culture (Ando, 2009).

To evaluate the effects of the program in Mexico on English language skills, students were asked to take the TOEIC test after returning to Japan. TOEIC is a popular English test in Japan, operated by ETS (Educational Testing Service) which provides TOEFL as well. Many Japanese universities use TOEIC to measure English proficiency of students. The results for the ten years of the program indicated a significant difference in the TOEIC scores after returning to Japan (Figure 6). While the TOEIC score remains low, after returning to Japan, students' practical knowledge in various fields such as agro-environmental studies, social science, health, Latin culture, and communication skills improved.

The Overseas Practical Education Program in Uganda is the most recently implemented program, started in 2015. Students spend three weeks at the College of Agricultural and Environmental Sciences, Makerere University (Kalemelawa, 2017a). Preliminary results obtained in 2015, after just one year of study, demonstrated 
improvement in students' global human capital development, global knowledge and global communications skills (Kalemelawa, 2017b). However, because the program only launched recently, we are measuring the impact of this program on Japanese students to strengthen the statistical analysis.

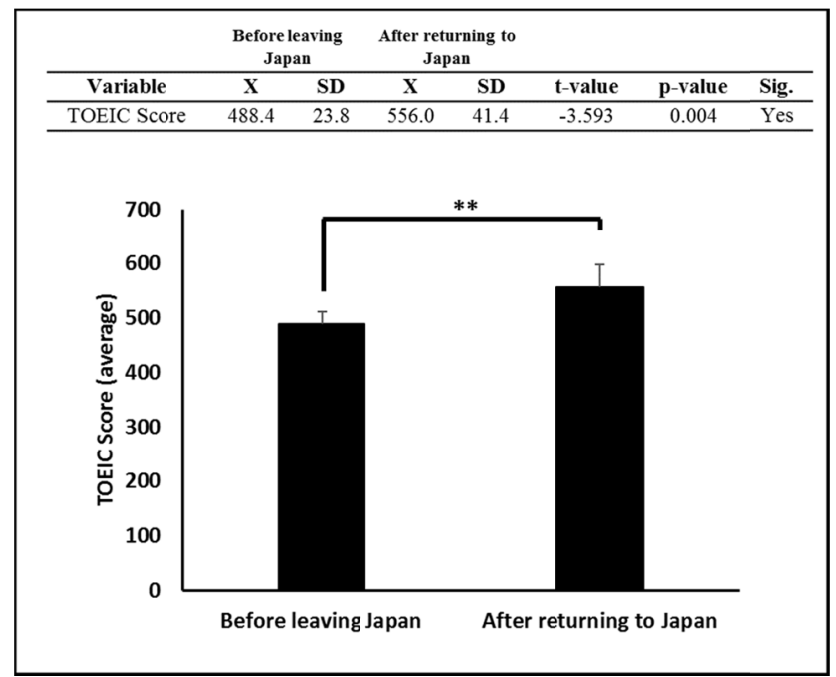

Figure 6. Average score for the TOEIC of students who attended the overseas practical education program in Mexico. The values represent the average and standard deviation. The asterisk indicates significant differences before and after GGP implementation (**t-test, $\mathrm{p}<0.01$ )

\subsection{TU On-Campus English Courses Stimulate the First Step Towards Travelling Abroad}

Other than the overseas programs offered by TU, a number of domestic programs are also available to Japanese students to improve their language and global competence skills on-campus. The most important of these programs stimulates the interest of new students who enter university or, students who have no experience of overseas study. These programs include language support courses, domestic English immersion programs, and global education courses taught by foreign teachers.

To assess the effect of these domestic programs, we analyzed the TOEIC scores of each faculty from 2012 when the GGP was implemented and again at the time of graduation in 2016 when the GGP was completed. The results indicated that the percentage of Japanese students with a TOEIC score of more than 600 increased from $3.6 \%$ in 2012 to $8.1 \%$ in 2016 (Figure 7). This emphasizes the positive effect of the GGP on TU students and their interest in improving English skills as a communication tool. While participation in overseas short-term programs and the TOEIC score is still low, students who study abroad for even a short period can shape and change their perceptions, which is a big step for the TU international and global understanding strategy.

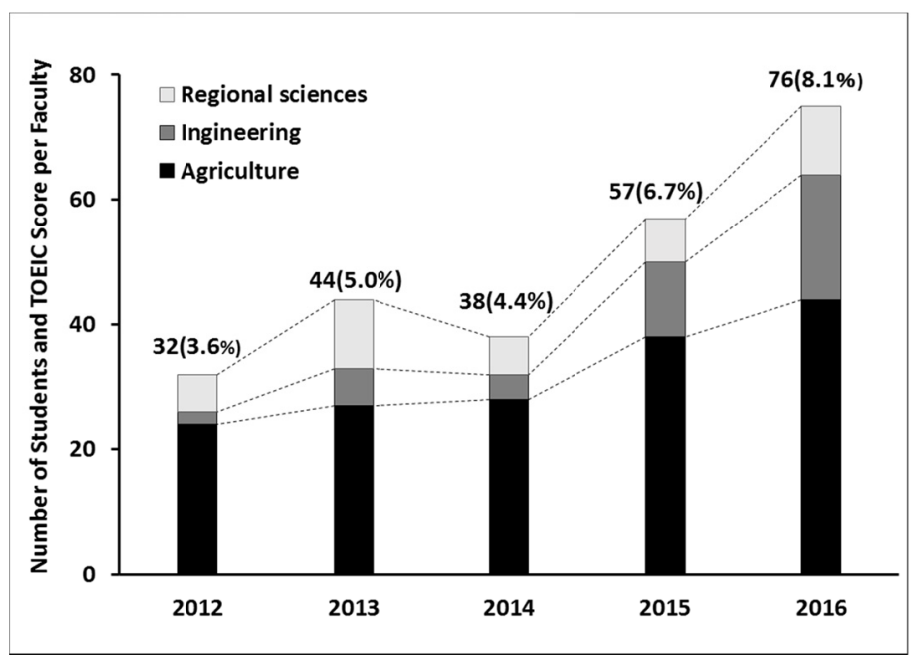

Figure 7. Number of students per faculty at TU with a TOEIC score of 600 or more at the time of graduation in 2016 


\section{Discussion}

The human being is a social creature that cannot live by itself. People always experience problem relating to others to maintain their lives (Baumeister, 2005). Herein lies the foundation of education. The concept of collaboration has been defined in various fields thus far. Ikeda and Tateoka (2007) contended that Japanese language education should develop a multicultural symbiotic society, highlighting equality, dialogue, process, creation, and reciprocity as key concepts of collaboration. As such, the goal of TU is to create comprehensive short-term overseas programs to develop global human resources based on English communication, intercultural understanding and basic practical education skills. By dispatching students overseas, TU is enabling self-growth based on experience and awareness through multiple exposures to the ACT cycle (Awareness $\rightarrow$ Change $\rightarrow$ Trial) proposed in our project in 2012 (http://www.jsps.go.jp/j-gjinzai/data/shinsa/h24).

Participating in overseas programs has recently become popular as an international strategy and is growing exponentially (Cisneros-Donahue et al., 2012). However, in Japan the number of students going overseas has continued to decline since the mid-2000s (Lassergard, 2013), and it was reported that $44 \%$ of Japanese people were not interested in traveling abroad. According to the Recruiting Experts Worldwide (Hays) 2013, the main concerns reported were language, communication, and, as well as that young people are trying to avoid changes in their lives (Katori, 2016). Therefore, to increase the interest of Japanese students, newly entered to university, in going overseas, English immersion programs on campus and overseas English language programs were established through the GGP. The English overseas programs enable students to participate in local language courses to improve their ability to communicate in English. This has become a long-term task in Japan (Sasaki, 2007; Morita, 2010; Kimura, 2011; Nishikawa, 2013). In addition, to further increase the interest of Japanese students in travel outside of Japan, English language with cross-cultural understanding programs were launched. These new programs have increased the number of participating students from all facilities and academic grades. Our results for gender are similar to those of other authors, who reported that females are more likely to study abroad and have more positive intercultural attitudes than men (Kim \& Goldstein, 2005; Pope et al., 2013). However, further research is needed to clarify whether the increase in female students in overseas programs at TU was due to the implementation of the GGP and not due to demographic differences.

Participation in language programs or language/cross-cultural programs is the first step towards obtaining a global mindset, because students become aware of the significance of understanding the world and themselves, which encourages them to participate in overseas practical education programs in developing countries, the final goal of TU. However, why is TU promoting overseas practical education in developing and emerging nations?

In the past, practical education in Japan referred to "practice" or "training," in other words, the term "practical training education" was used as a form of education through existing teaching methods that focus on existing knowledge and skills (Suzuki, 2017). However, the skills needed in a global society extend beyond the skills and knowledge effective in the past. Nowadays, practical education should be conducted as the practical ability to live socially and discover and solve problems, because relationships with others are changing alongside changing education needs and the environment (Ikeda \& Tateoka 2007). Therefore, the receiving party of education must understand that improving communication skills including English skills will help them become globalized human resources. As such, we are trying to cultivate English skills through our practical overseas programs in developing and emerging nations.

Through practical education, TU exposes students to continuous stimuli through which they put into practice what they learned in the classrooms. However, most important is their exposure to several problems related to culture, food, the environment and communication, to which they must provide solutions. As far as possible, real situations students might encounter outside the classroom are used. Through these experiences, students understand the importance of field practice in addition to knowledge acquired in the classroom, as well as how to behave in societies with different beliefs, cultures, and languages and why English as a tool for communication will help them develop as internationally-minded future leaders for our rapidly changing global society.

In this study, we found that the TOEIC scores after attending overseas programs increased to between 550 to 600 , which is still considered low compared to the scores at other Japanese universities. As TOEIC score only shows language proficiency, we do not focus on the TOEIC score itself for global education. The reason why we asked the student to take the TOEIC test after returning to Japan is that TOEIC score motivate students to improve their global awareness, as well as a TOEIC score is a convenient tool for students to evaluate themselves subjectively. In other words, we consider a TOEIC score as the start point of subjective and autonomous global education for students. As a matter of fact, students may set the goal of improving their TOEIC score. As it is common for students to use TOEIC scores under conventional education circumstances, it should not be removed but it 
should be used initiatively. Katori (2016) reported that short-term studies abroad do not have a statistically significant effect on English proficiency. However, participants reported positive changes and improvement in a range of skills including global and cultural awareness, confidence, and interpersonal, and intercultural communication skills. The questionnaires completed by undergraduate students who participated in overseas programs at TU revealed that all felt they had become aware of global issues and most had acquired a solid set of global competence abilities.

We revealed the significance of the English overseas programs as a communication tool, and how foreign languages can develop practical skills to use overseas. Our final goal is to foster students with "tough and practical global talent" who at the time of graduation are equipped with the three global competences: global human potential, global literacy and global communication skills, which are required in a global society. Furthermore, they must be ready to challenge the world or work for Japanese companies with requirements for global human resources.

We can report various examples of TU students who attended their first English immersion programs on campus, English programs or English with cross-cultural understanding programs abroad and then an overseas practical program in Mexico or Uganda. After attending one or more of our three types of programs, students were confident enough to apply to the Young Ambassador Program (Tobitate Ryugaku Japan- "Leap for tomorrow"), a public-private partnership launched in 2014 that promotes Japanese students studying overseas. The program is sponsored by MEXT and public-private Japanese companies (http://www.tobitate.mext.go.jp/about/english.html). Some were not successful in their applications, but remained motivated to train overseas. One student who participated in overseas practical education in Mexico in 2011, after returning to Japan and graduating from a Master's program, started to work at the Japan International Cooperation Agency (JICA) and is now employed at NTC International Co., Ltd in Japan.

An excellent example of achieving the TU goal is one student who attended the domestic English immersion program during the first year in 2013, English program in Taiwan during the second year in 2014, overseas practical education in Mexico during the third year in 2015, partnership program Japan-Mexico sponsored by the Ministry of Foreign Affairs during the fourth year in 2016, and who was finally selected by the Tobitate program in 2017. Many other cases can also be described in which students mentioned their satisfaction for being able to express their own ideas in public. Most important is that these students are now potential human resources with a set of global competences who can contribute positively to Japanese society.

TU also offers an International Training Program (TU-ITP) in the Arid Land Center where Master's students are dispatched in Jordan, Italy and China to develop their graduate research plan followed by field research. The aim of the program is to contribute to a global pool of professionals who can address challenges in arid land areas.

Nakamura (2002) noted that globalization does not mean westernization. Participation in overseas programs does not mean that Japanese students will lose their own culture or Japanese spirit. In contrast, after attending programs abroad, students will better understand their own culture and be proud to have been born in Japan. Furthermore, they will have the necessary skills to live in a multicultural society.

TU is now moving towards recruiting new Japanese students and providing them with the opportunities to challenge the world through the overseas programs as part of global education. We are also focusing on developing new strategies to increase the number of foreign students and create mutual education through collaborative learning. In addition, we are in the process of transforming our existing English and cross-cultural understanding programs into a more practical offering, combining language learning, lectures and fieldwork based on the local characteristics of each country. In these programs, students will have the opportunity to practice what they learned in the classroom.

\section{Concluding Remarks}

We described the positive effect of short-term domestic and overseas programs on TU Japanese students, and the importance of "practical type" training programs as a part of TU international strategy in developing countries. The questionnaires completed by students reveal their satisfaction with participating in overseas programs. Specifically, the enhancement of English skills contributed positively towards better understanding the culture of others and global issues, and improved their confidence to express themselves in public. We do not deny that the development of English communication skills and foreign languages is very important in the development of global human resources. However, in addition to the educational aspect, students must understand what communication skills are and why these will empower them in the future. 


\section{Acknowledgments}

This work was supported by the "Go Global Japan" Project for the Promotion of "Global Human Resources Development" type B for Tottori University supported by the Ministry of Education, Culture, Sports, Sciences and Technology (MEXT) FY2012-2016.

\section{References}

Ando, T. (2009). Mekishiko Kaigai jissen kyoiku puroguramu karikyuramu [Overseas Practical Education in Mexico Curriculum]. Journal of Education Center Tottori University, 14, 5-6. (In Japanese).

ANESTA. (2018). Global ka ni chosen suru daigaku. Retrieved from https://www.anesta.co.jp/user/cn10/pg202.html. No. 06 (In Japanese).

Baumeister, R. F. (2005). The cultural animal: Human nature, meaning, and social life. New York: Oxford University Press.

Bradford, A. (2015). Changing trends in Japanese students studying abroad. International Higher Education, 83, 22-23. http://doi.org/10.6017/ihe.2015.83.9086

Butler, Y. G. (2007). Foreign language education at elementary schools in Japan: Searching for solutions amidst growing diversification. Asia-Pacific Education, Language Minorities and Migration (ELMM), Network Working Paper Series. 3.

Cisneros-Donahue, T., Krentler, K. A., Reinig, B., \& Sabol, K. (2012). Assesing the academic benefit of study abroad. Journal of Education and Learning, 1(2), 169-178. http://dx.doi.org/10.5539/jel.v1n2p169

Council of Europe. (2011). The Common European Framework of Reference for Languages (CEFR): Learning, Teaching, Assessment. Cambridge University.

Hashimoto, K. (2013). "English-only," but not a medium-of-instruction policy: The Japanese way of internationalising education for both domestic and overseas students. Current Issues in Language Planning, 14(1), 16-33. https://doi.org/10.1080/14664208.2013.789956

HAYS [Recruiting experts worldwide]. (2013). Gen Y and the world of work. A report on the workplace needs, attitudes and aspirations of Gen Y Japan.

Hishida, M. (2015). Tottori daigaku no global jinzai ikusei suishinn jigyo no torikumi. Journal of Education Center Tottori University, 20, 46-51. (In Japanese).

Horiguchi, S., Imoto, Y., \& Poole, G. S. (2015). Foreign language education in Japan: Exploring qualitative approaches. Rotterdam: Sense Publisher.

Ike, M. (1995). A historical review of English in Japan (1600-1880). World Englishes, 14(1), 3-11.

Ikeda, R., \& Tateoka, Y. (2007). Pia raningu nyumon-Sozo tekina manabi no dezain no tame ni [An introduction to peer-learning-for creative learning design]. Hitsuji Shobo Publisher. pp 152. (In Japanese).

Japan Students Services Organization [JASSO]. (2010). Results of an annual survey of international students in Japan. Retrieved from http://www.jasso.go.jp/en/about/statistics/intl_student_e/2010

JASSO (2015). Results of an annual survey of international students in Japan. Retrieved from http://www.jasso.go.jp/en/about/statistics/intl_student_e/2015

Kalemelawa, F. K. (2017a). An overview and guide to the Tottori University overseas practical education program at Makerere University-Uganda. Journal of Education Center Tottori University, 22, 31-41.

Kalemelawa, F. K. (2017b). Students Pre and Post Observations and perspectives in the 2015 "Overseas Practical Education Program" in Uganda. Journal of Education Center Tottori University, 22, 42-48.

Katori, M. (2016). The trends of Japanese student's participation in study abroad programmes. US-China Foreign Language, 14(3), 239-249. https://doi:10.17265/1539-8080/2016.03.007

Kim, R. I., \& Goldstein, S. B. (2005). Intercultural attitudes predict favorable study abroad expectations of U.S. college students. Journal of Studies in International Education, 9, 265-278. http://doi:10.1177/1028315305277684

Kimura, K. (2011). How effective is for the short-term studying program in an English-speaking country is for Japanese university studies: Focusing on the listening and writing proficiency. Journal of Shobi University Policy Management, 21,17-30. http://doi: 10.1111/j.1744-6155.2011.00297 
Kirkpatrick, A. (2011). English as an Asian lingua franca and the multilingual model of ELT. Language Teaching, 44(2), 22-224. http://doi.org/10.1017/S0261444810000145

Kuwamura, A. (2009). The challenges of increasing capacity and diversity in Japanese higher education through proactive recruitment strategies. Journal of Studies in International Education, 13(2), 189-202.

Lassegard, J. (2013). Students perspectives on international education: An examination into the decline of Japanese studying abroad. Asia Pacific Journal of Education, 33(4), 365-379. http://doi.org/10.1080/02188791.2013.807774

Lawson, C. (2012). Japan's new growth strategy: Internationalisation of Japanese universities. Australian Education International, p. 50.

Ministry of Education, Culture, Sports, Science and Technology [MEXT]. (2014). Selection for the FY2014 Top Global University Project. Retrieved December 26, 2017, from http://docplayer.net/16379288-Selection-for-the-fy-2014-top-global-university-project-we-hereby-announce -the-selectionof-universities-for-the-top-global-university-project.html

Morita, M. (2010). How does a short term study abroad influence language learning strategies? -The case of the intercultural communication program at Yamagata University. Yamagata University, 7, 23-36.

Nakamura, K. (2002). Cultivating global literacy through English as an international language (EIL) education in Japan: A new paradigm for global education. International Education Journal, 3(5), 64-74. http://doi:10.1.1.116.2825

Nam, M. (2018). Study-abroad experiences of two south Korean undergraduate students in an English-speaking and a non-English-speaking country. The Asia-Pacific Education Researcher. https://doi.org/10.1007/s40299-018-0376-3

National Institute on Aging. (2007). Why Population Aging Matters: A Global Perspective.

Nishikawa, M. (2013). The effectiveness of a preparatory English course and study-abroad programs on improving student's communicative skills: Base don the analysis of a pre-departure IELTS. Journal of Organization for the Promotion of the International Relations (Kyoto University), 3, 61-72.

Okada, N., \& Okada, A. (2013). The new development of internationalization in Japanese higher education. Asia Pacific Journal of Educational Development, 2(1), 27-35. http://doi:10.6228/APJED.02.01.03

Organization for Economic- Co-operation and Development [OECD]. (2012). Education at the Glance 2012. Paris.

Phan, L. H. (2013). Issues surrounding English, the internationalization of higher education and national identity in Asia: A focus on Japan. Critical Studies in Education, 54, 160-175. http://doi.org/10.1080/17508487.2013.781047

Pope, J., Sánchez, C. M., Lehnert, K., \& Schimid, A. S. (2013). Why do Gen Y students study abroad? The relationship between individual growth and the intent to study abroad. Developments in Business Simulation and Experimental Learning, 4, 25-28. http://doi.org/10.1080/08975930.2014.896232

Rose, H., \& McKinley, J. (2018). Japan's English-medium instruction initiatives and the globalization of higher education. High Education, 75, 111-129. http:// doi.org/10.1080/08975930.2014.896232

Sasaki, M. (2007). Effects of study-abroad experiences on EFL writers: A multiple-data analysis. The Modern Language Journal, 91(4), 602-620. http://doi.org/10.1111/j.1540-4781.2007.00625

Seargeant, P. (2011). English in Japan in the era of globalization. New York: Palgrave Macmillan.

Shimomura, H. (2013). Making Japanese higher education more international. The Japan Times. Retrieved from http://info.japantimes.co.jp/ads/pdf/20130902_global_30_universities.pdf

Suzuki, H. (2017). Kyoku gokko wo koeru kanosei wa aru no ka? [Beyond educational pretend play: Towards embodied knowledge]. Journal of Japan Association for College and University Education, 39(1), 12-16. [In Japanese].

United Nations Educational, Scientific and Cultural Organization [UNESCO]. (2013). The International Mobility of Students in Asia and the Pacific. Asia and Pacific Regional Bureau for Education. Bangkok Office.

Yonezawa, A. (2014). Japan's challenge of fostering "Global Human Resources." Policy debates and Practices. Japan Labor Review, 11(2). 


\section{Copyrights}

Copyright for this article is retained by the author, with first publication rights granted to the journal.

This is an open-access article distributed under the terms and conditions of the Creative Commons Attribution license (http://creativecommons.org/licenses/by/4.0/). 